1935

\title{
Diagnosis gallbladder disease
}

Jack I. Limburg

University of Nebraska Medical Center

This manuscript is historical in nature and may not reflect current medical research and practice. Search PubMed for current research.

Follow this and additional works at: https://digitalcommons.unmc.edu/mdtheses

Part of the Medical Education Commons

\section{Recommended Citation}

Limburg, Jack I., "Diagnosis gallbladder disease" (1935). MD Theses. 635.

https://digitalcommons.unmc.edu/mdtheses/635

This Thesis is brought to you for free and open access by the Special Collections at DigitalCommons@UNMC. It has been accepted for inclusion in MD Theses by an authorized administrator of DigitalCommons@UNMC. For more information, please contact digitalcommons@unmc.edu. 


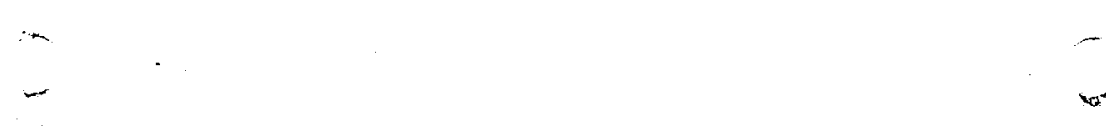

TIS DIAGNOSIS OF GAII BIDDDUR DISEASE

This thesis is respectully submited to the faculty of the University of Nebrask ollege of bedicine as a partial recuirement for a degree of Doctor of ledicine.

-- J.I. Iimburg

Mril, 26, I935

Omahe, Nepraske. 
INDTX

Anstomical Consiceration

rere I.

Generel iscussion

Etjods of Dirchosis

6

His tory

Iethods of Fhysicel Examination $\cdot 8$

$\mathrm{X}$-ray uxamination II

Intubation IE

Differential Diagnosis by leans of Intubation 20

Iroducts of Intubetion lay Sugeest Stones 24

Blood Cheristry in Diachosis 25

Telationship of leart ana Coll Blader isease 27

Gall stones and Feart Disease 27

cute Cholecystitis ae

Clinicel Diagnosis, 30

Chronic Cholecystitis 32

Additionel Clssificetion 33

Differential Diecnosis 35

Bibliograyhy $\therefore 4$ 


\section{DIAGNOSIS OF GAIL BLADDER DISEASE}

ANATON ICA CONSIDERATIONS

This paper dealing with the diagnois of gall blacuer disease nust necessarily inclucie a few vords on the anatomy of the liver, gall bladcer, and ducts.

The liver arises in the form of a diverticulum or hollow out rowth from the ventral surface of thet portion of the gut which afterward becomes the descending rart of the duodenum. This diverticulum is lined by entoderm, and Erows upwerd and forward into the sertum trensversur, a mass of mesocerm between the vitelline duct and the precardial cevity, and there gives off two solid buds of cells which represent the right and left lobes of the liver. The solid buds of cells erow into colums or cylinders, termed the hepatic cylinders, which branch and anastomose to form a close network. This meshwork invades the vitelline ana umbilical veins and breaks up these vessels into a series of capillary-like vessels terred sinusoids, which ramify in the meshes of the celiur network and ultimately form the venous capilleries of the liver. By the continued growth and ramification of the hepatic cylinders the mas of the liver is eradually formed. The original diverticulum of the duodenum forms the comon bile duct, and from this the cystic duct and gall bladder arise as a solid growth which later acquires c. luren. The orening of the comcon duct is at first in the ventral wall of the duodenum; later, owing to the rotation of the gut, the onening is carried to the left and then dorsalvard to the position it occupies in the coult

The bile ducts comence by little passages in the liver cells which conmunicate with the cenaliculi wich are termed intercellular biliary gassages. These passages are werely little channels or spaces left between the contiguous surfaces of two cells, or in the angle where three or wore liver 
cells meet, and they are always separated frow the blood capillaries by at least half the width of the liver cell. The channels thus formed radiate to the circumference of the lobule, and open into the interlobular bile ducts which run in Glisson's capsule, accompenying the portal vein and hepatic artery. These join with other ducts to form two main trunks, wich leave the liver at the transverse fissure, and by their union form the heyatic duct. The walls of the biliary ducts consist of a connective-tissue coat, in wich are ruscle cells arranged both circularly and longitudinally and an epithelial layer, consistine of short columar cells resting on a distinct basement membrane.

The excretory arparatus of the liver should be considered as beine gert of the liver and no discussion of the gall bladder is complete ithout mention of the duct system. The excretory arraratus of the liver consists of the heqatic duct formed by the junction of the tro rain ducts, which pass out of the liver at the porta; the gall blader, which serves as a reservoir for the bile; the cystic duct, or the duct of the gall bladder; and the comron bile duct, formed by the junction of the hepetic and cystic ducts.

Two main trunks of nearly equal size issue from the liver at the ports, one from the right, the other from the left lobe; these unite to form the hepatic duct, which passes downward and to the right for about 4 cri., between the layers of the lessor omentum, where it is joined at an acute angle by the cystic duct, and so forms the common bile duct. The hepatic duct is accompanied by the hepatic artery and portal vein.

The gall bladder is a conical or pear-shaped musculomembranous sac, lodred in a fossa on the under surface of the right lobe of the liver, and extendine from near the richt extremityr of the porta to the enterior border of the orcan. It is from 7 to $10 \mathrm{~cm}$. in leneth, $2.5 \mathrm{~cm}$. in breadth at its widest part, and holds from 30 to $35 \mathrm{c.c}$. It is civided into a fundus, 
body, and neck. The fundus, or broad extremity, is directed downwerd, forward, and to the right, and projects beyond the anterior border of the Iiver; the body and neck are directed upwrd and backwrd to the Ieft. The upper surface of the gall bladaer is attacked to the liver by connective tis ue and vessels. The under surface is covered by peritoneum, which is reflected on to it from the surface of the liver. Occasionally the whole of the organ is invested by the serous memorane, and is then connected to the Iiver by a kind of mesentery.

The cystic duct about 4 cri. Ions, runs backvera, downwerd, and to the left from the neck of the gall klacier, and joins the hepatic duct to form the common bile duct. The mucous membrane lining its interior is thrown into series of crescentic folds, from five to twelve in number, similar to those found in the neck of the gall bladjer. They project into the duct in regular succession, and are directed obliquely around the tube, jresenting much the appearance of a continuous spiral valve. When the duct is distended, the spaces between the folds are dilated, so as to eive to its exterior a twisted epearance.

The common bile auct is formed by the junction of the cystic and heratic ducts; it is about $7.5 \mathrm{~cm}$. 1ong, and of the diameter of a goose quill.

It descenas alone the right boraer of the leswor onentum behing the superior portion of the duodenum, in front of the portal vein, and to the right of the hepatic artery; it then runs in a groove near the right border of the posterior surface of the hea of the pancras; here it is situated in front of the inferior vena cave, and is occasionally completely imbedded in the pancreatic substence. At its teruination it lies for a short distance along the right side of the terminal part of the pancreatic duct and passes with it obliquely between the mucous and muscular coats. The two ducts unite and open by a common orifice upon the sumit of the duoderal papilia, situat 
s.t the medial side of the cescending portion of the duodenum, a little below the midale and about 7 to $I 0 \mathrm{~cm}$. from the pylorus. The short tube formed by the union of the two aucts is dilated into an ampulla, the ampulla. of Vater.

\section{GENEAL DISCUSSION}

It has been roughly calculated that over twenty-percent of ail the adults presenting symptoms referable to the digestive tract have patholocy in the gall bladder.

The diagnosis of cholecystic disease is often not easy. A typical clinical pictures are very confusing to the clinician and frequently it is impossible to make a definite diagnosis. Since the introduction of the Grahsir Cole nethod of visualizing of the gall bladder, a renewed interest has been stimulated in an attempt to make an earlier diagnosis of cholecystic disease. This method of examination has roved itself to be a great aid to the diagnostician. Nuch has been claimed by certain writers for the value of lieltzer-Iyons method of studing the biliary fluid by means of a duodenal tube. Many who have given this test a fair trial feel that its value can be seriously questioned.

Without question the most important single diagnostic procedure is the securing of careful history dating back to the first appearance of digestive disturbance or pain. The patient of ten needs considerable prodding in order to remember the mild pains of digestive upsets that occurred a number of years before. Complete freedom from distress of any kind may be present for years after the initial attack.

The symptomatology of gall bladder disease has its origion either in the over-distended gall bladder itself or. by reflex or direct action of the diseased gall bladder on the adjacent organs, notably the stomach, pencreas, and intestinal tract. "Reverse peristals is syndroms" plays a 
very prominent part in the production of the discomfort. These symptoms are nausea, vomiting, belching, bloating and pyxosis. Although these are present in many states causing a icestive disturbances, including that large Eroup called functional indigestion, it is believed by men authorities that this syndrone is often an early finding in cholecystic disfunction. It is difficult to find any particular food that uniformily cause these patients distresa. Fats are said to be eaten with difficulty. The patient. is always searching for a cause, and usually ascribes it to something that was eaten in a previous meal. I do not believe it has been proven that any particular food or foods are capable of producing an attack. The only physical findings that seem to be of any importance are tenderness, palpation of the enlarged fall bladder, and jaundice. of these, tenderness is by far the most frequent and most importent sign. When present it is an extremely valuable finding, but its absence should not misled the clinician in his search for gall bladder disease. When ordinary palpation fails, tenderness can often be eliciated by having the ratient sit up and lean forward; then, with the physician behind, the examing fingers can be pressed deeply under the ribs.

Falpation of the gall bladder is extremely difficult unless there is gross pathology such as empyena or cancer. When it is palpable, it always means that a pathological condition is present. Jaundice, contrary to ordinary beliefs, is not of frequent occurrence. Some authors state that jaundice occurs in only eight per cent of cases of gall blacier disease.

The gall bladder must be considered as an integral part of the hepotoenteric systems. We must think of the liver as one unit and the intestinal tract as the other unit, and the two associated by connecting links which the French call the hepotoenteric circulation. This canception. 
is vitally important, as it emphasizes the complete dependence of one link of the chain on the other portion, the afferent chain connecting the digestive tract to the liver and the biliary tract, the great efferent chain. The Iiver, like the kidneys, is in a large degree the excretory organ. The biliary tract is the transit system for bile, and the gall bladder is a diverticulum in the course of this transit system. It certainly plays no very active part in upper abdominal digestion. The lack of the organ in many animals and the comparatively unimpaired digestion which occurs in individuals who have been submitted to cholecystectomy bear out this view. Twenty-five years ago the diagnosis of gall bladder disease was confined to those cases with biliary colic and sharply circumscribed pain in the upper right quadrant. Today, owing to modern methods and by a more perfect correlation of surgical and medical material, the refinement of biliary tract diagnosis has aproched that stage where it is possible to assume that many forms of gall bladder diaease do not present this classical picture.

Gall bladder disease rarely exists alone. There is an abundance of clinical and surgical evidence to prove that the liver is usually implicated Jany authors have emphasized and proved beyond a doubt that liver disease is a common association of biliary tract disease. Some men go so far as to contend that there is lym hatic drainage both ways, from the gall bladder to the liver and vice versa.

\section{IETHODS OF DIAGNOSIS}

Gall bladder diagnosis two decades ago consisted in a well taken history and a careful examination. Today it consists of the same procedure amplified by methods which throw more or less direct light on gall bladder function and pathology. We have at our disposal the following methods: 
(I) HISTORY (2) FHYSICAL BXANINATION (3) X-RAY EXMINATION (4) DUODENAL INTUBATION (5) STUDY OF BLOCD SERUL, notably the Van den Bergh reaction, the icterus index, blood cholesterol and so forth.

\section{HISTORY}

Let us consider for a moment the history. A history of biliary colic or sharply defined upper right-sided pa in more or less circumscribed to the biliary region and in the right upper quadrant is encountered in the majority of cases.

Fain in gall bladder disease is due to two factors: first, acute inflamation of the gall bladder per se, and second, muscular spasm set up by the presence of a calculus in the duct. The rain in cholecystitis varies according to whether or not there is a stone attempting to pass along the cystic duct. When there is a stone, the pain is Eenerally localized to the region of the gall bladder, or if there be contiguous peritonitis, adhesions, or bands the pain may be diffused over the right side and even to the chest or to the left side. If the liver and gall bladder are much enlarged downward, the pain may extend down to the iliac fossa and even down to the lower extremities. When there is a stone in the neck of the gall bladder or in the cystic duct, the pain radiates also to the area beneath the inferior angle of the right scapula. This corresponds to the level of distribution of the eighth dorsal segment from which the gall bladder derives its main nerve supply. In uncomplicated cases, pain is not felt in the right acromial or clavicular regions, but in the right hypochondrium or in the epigastrium alone.

In a review of the literature, we have arrived at the conclusion that pain in gall bladder disease is as variable as the pain in appendicitis. In other words, the pain may vary fram the anginal type to one resembling 
that of a retroversion.

\section{WTEODS OF FHYSICAI IXAUINATION}

In the physical examination, nothing is more suggestive of gall bladder disease than residual tenderness at or near the tip of the ninth costal cartilage and more pronounced on upward pressure. A tumor of the gall bladder is (I) empyena; (2) hydrops, usually associated with stone in the cystic duct; (3) carcinoma; and (4) an occasional gall, bladder filled with stones. Rigidity of the uprer right rectus, cutaneous hyperesthesia localized to the gall bladder area are of value.

Duodenal intubation is now a standard method of biliary tract investigation, and will later be discussed in more detail.

For the successful treatment of any disease it is an absolute preliminary requisite that we have a sound diagnostic conception of the diaease to be treated. If adequate diagnosis is required to work out the beginning details of the comparatively easy diagnostic picture of acute mastoiditis or acute appendicitis, how wuch more difficult does differential diagnosia become when we find ourselves dealing with relatively vague pictures of chronic digestive disorders which have not progressed to the classical symdromes or clear cut clinical entities?. These are days when we are beginning to realize the importance and value of making comFlete diagnostic surveys of all patients, but particularly those presenting long continued symptoms of ill health, and no diagnostic survey is complete without a most careful study of the gastro-intestinal tract, and not alone by means of the roentgen ray or simple test meal analys is. The cause of much chronic invalidism will be found to lie here.

Wuch has been said recently in criticism of the tendency in wedicine Tof today to develop diagnosis by means of endless charts, curves, graphs 


\section{(9)}

and laboratory formalae, and to sit back and admire such handiwork, perhaps at the expense of failure to make skillful use of the five senses employed to such advantage by our medical forefathers. Certainly neither one of these extremes is alone correct. They should be wisely combined, each with a consideration of what can be eained by the other, but with a neglect of neither. Surely the doctor of two or three generations ago, if his medical education had not frown with the times, would be unable to successfully compete with the best of today if his whole dependence lay in the skillful use of his five senses.

In palpating for gall bladder tenderness it will be found that the right upper rectus is slightly more resistant normally than is the left upper rectus perhaps on account of the lower position of the right lobe of the liver. This is a normal and physiological difference similar to the slightly increased percussion dulness of the posterior upper fole of the right lung as compared to that of the left lung. The usual point of gall bladder tenderness will be found in the upper third of a line drawn between the ninth rib and the navel. It thus very closely merges with the usual point of duodenal tenderness which lies at about the middle point of this line.

In examining for tenderness in the region of the gall bladder or gall ducts bimanuel thumb pressure should always be employed at some stage of the exanation. For this the ratient should be lying on his back with the head and neck sIightly raised and the knees comfortably flexed over a pillow, or with the soles of the feet comfortably placed on the bed. The examiner, sitting on the right side of the patient, places the thumb of each hand in each hypochrondrium at the tip of the ninth ribs with the palm and 
fingers more lightly grasping at the costal margins. With the patient niceIy relaxed, after each successive deep inspiration the thumbs at expiration are more and more firmly pressed up under the soctal margins. When the gall bladder or gall ducts are the seat of inflammation, even of slight degree, after the thumb has been firmly rressed upward on expiration, a further full inspiration will not only elicit pain, but will interfere with the free respiratory movemeat of the diaphram on the right side. when there are acute inflammatory adhesions or some localized peritoneal irritation there will also be brought out, as a rule, some protective rigidity and spasm of the upper right rectus muscle.

Another common way of eliciting gall bladder pain to for the examiner to stand on the right side of the patient, but facing his feet, and with the fingers of the left hand tightly grasping and pressing under the right costal margin in the neighborhood of the ninth rib the patient is instructed to take deep respirations, and at the end of a deep inspiration the examiner smartly strikes the knuckles of the left hand with the closed $f$ is $t$ of the right hand. This maneuver will almost invaribly bring forth an exclamation of pain or distress from the patient possessing an inflammed gall bladder. In certain instances in which the upper right quadrant is in a state of intense muscle rigidity and spasm it may occasionally be necessary to put the patient in a tub full of hot water which will so help to relax the abdominal muscles as to mke palpatory examination more easy. Another maneuver for eliciting gall tract tenderness when the gall bladder or ducts are inflammed is by ulnar concussion described by Riesman. This consists of having the patient take and hold a full inspiration when the examiner strikes in turn both the upper right and the upper left quadrant with the uInar edge of the hand. The examiner learns to differentiate 
Eastric from gall tract inflamation by comparing the subjective response to localized tenderness on the part of the ratient in the left upper quadrant with that in the right.

\section{X-RAY IXALINATION}

Roentgenography is especially valuable as a diagnostic aid in determining the extent and location of pathologic changes found in the gall bladder and adjacent organs. The sympathetic nervous system, through the superior and inferior mesenteric ganglia, receives fibers from the right kidney and ureter. Also from the stomach, duodenum and the right colon and gall bladder. This causes much difficulty in detecting which organ may be responsible for pain situated in this region. As an example, kidney and ureteral lesions are found frequently with pronounced gastro-intestinal symptoms, particularly of nausea and vomiting. Cholecystitis, with or without cholelithiasis, may simulate closely duodenal or gastric ulcer and diseases of these organs may simulate gall bledder disease.

It is in cases of this type that roentgenology in the hands of a competent roentgenologist manifests itself as a most valuable procedure, for by a process of elimination the correct solution of the problem can usually be made. But the mere taking of roentgenograms often contributes nothing to the diagnosis. This particularly applies to the lesions of the gastro-intestinal tract and often a correct diagnosis can be made by a skilled fluoroscopist. In many instances the films do not demonstaete the lesion definitely. The development of this branch of medicine through new methods and improved technic has brought about a change in the operative schedule in hospitals and the frequent necessity for exploratory operation a decade or so ago is no longer prevalent.

The roentgenographic diagnosis of a specific lesion may not always be 
a solution of the problem, for quite frequently more than one organ may be involved. For example, a patient with a diseased appendix may also have a duodenal ulcer or a gall bladder lesion.

The dye test is of unquestioned aid in the differential diagnos is of gall tract disorders. Never the less, several conditions must be kept in mind lest the shadow of supposed gall-stone or an absence of gall bladder visibility tempt an over anxious surgeon. A renal calculus in a lateral film will definitely determine the location of the stone. Calcified mesenteric glands likewise cause suspicious shadows. Gas bubbles many times present shadows which are most suggestive of calculi. However successive films at subsequent hours will rule out this possibility. Occasionally in a hypermotile stomach the capsules will be so rapidly ejected into the intestine that the dye will pass beyond the gall bladder. This is not a common occurrence and with careful observance of the schedule for administration at least a portion of the dye should reach the gall bladder. Cholecystography is but a new link in the diagnostic chain and with its use a. much more precise knowlede of the diseased gall bladaer is made possible. We would emphasize this fact, that it should not replace the other methods of diagnosis.

In I924 Graham and his associates found that when calcuim tetrabromphenolphthalein was injected into the veins it was excreted chiefly with the bile, and thus it was possible to depict the gall bladder in the roentgenogram. Sodium tetrabromphenolphthalein was then used as it was found to be as efficaciou and moch less toxic than the calcium salt. Improvements on the drug and its method of administretion followed rapidly after this preliminary work so that now examiners prefer to administer it orally. The technique employed by Kirklin at the layo. Clinic has proved 
(I3)

satiofactory. The patient is instructed to eat the usual amount of supper at 6 F.M. but without eggs, cream, butter or other fats, and, during or immediately after the meal, to take the iodine compound. This is dispensed to him in a single dose of $4 \mathrm{Gm}$, dissolved in $30 \mathrm{cc}$. of distilled water, and he is directed to $\mathrm{mix}$ it with a glassful of grape juice. Iaxatives are forbidden, but next moming he is required to cleanse the large bowel with a soapsuds enama. Breakfast is omitted, although water, black coffee or tea is allowed. At $8 \mathrm{A.M.}$, approximately fourteen hours after the dye was taken, the first set of roentgenograms is made with the patient thoroughly immobilized in the prone position and the rays directed through the back. At IO A.M. the second (sixteen-hour) set of films is exposed. The patient is then instructed to eat as desired at the noon hour, but to include with the meal a glassful of milk and cream or its equivalent in other fats as preferred. An hour after the meal the third, or twenty-hour, set of roentgenotrams is made.

Kirklin emphasized two of the foregoing techical features: (I) administration of the dye with or immediately after a full meal from which fats are excluded, and (2) complete immobilization of the patient during roentgenography. If the drug is taken after a light meal, or after digestion is well under way, nausea and vomiting are likely to ensue; if fats are included in the initial meal the shadow of the gall bladder is likely to be faint or absent. Novement, however slight, during roentgenography, will often obliterate evidance of stones or papillomata.

In broad terms, a normal cholecystogram is characterized by a aefinite, homogeneous, regularly contoured shadow of the bile that is impregnated with aye in the gall bladder, which changes in size and density at successive periods. Usually the shadow is denser at the sixteenth hour than at 


\section{(I4)}

the fourteenth hour; at the twentieth hour, the fat meal havine been taken in the meantime, the shadow most often will be considerably reduced in size and may disappear. As a general rule, the shadow will be slightly larger at the second period than at the first. This sequence as to size and density is not inflexible; the shadow may be most dense at any of the three periods and it may be largest at the first period. In short, no arbitrary st ndard can be set either for density or size. However, variation of size is an indication that the elasticity of the cystic wall is preserved, and if at any period the shodow is sufficiently dense to be visiole it can be assumed that the faculty of concentrating bile has not been lost. The shadow should always be homogeneous in the sense of not having persistent thin areas or dense spots. Neither the general form nor the position of the shadow has significance; in persons of the enteroptotic habitus the shadow is likely to be slender and situated low and toward the median line; in persons of broad habitus the shadow is usually rounded and seated high late rally.

Abnormal responses to the test comprise absence, faintness, mottling, Eross deformity, and unchanging size and density of the gall bladder shadow. The most common abnormal manifestation is failure of the gall bladder to cast a shadow in any of the serial roentgenograms. If the routine has been carried out as prescribed and without technical lapses, the total lack of a shadow is a highly defendable sign of disease, for it indicates either that the drug has failed to enter the gall bladder, or that the latter has been unable to concentrate the dye impregnated bile sufficiently to produce a shadow. Marked faintness of the shadow may be accounted for on similar grounds. Nottling may be caused by stones, or, occasionally, by -intracystic neoplasms. Stones with a high calcium content produce areas of 
intensified density within the shadow, whereas cholesterin stones appear as areas of rarefaction. It has been recently shown that papillomata, adenomata ar other new growths are manifested as transradient areas within the shadow. Frequently shadows of a stone are demonstrable without any shadow of dye, but by cholecystography a somewhat larger percentege of stones can be revealed than by former me thods, and the diagnosis can be made with greater assurance if the gell bladder is depictod. Deformity of the shadow, if pronounced, as in the case of hour-glass contraction, sharp angulation or marked distortion, may be due to pericholecystic adhesions from ancient or current disease, but deformity ithout other abnormal manifestation is a hazardous basis for diagnosis.

The rarefied mottled areas produced by cholesterin stones or papillomata may be imitated by collections of gas, in the bowel. Shadows of dense gall stones require distinction from those of calcified lymph nodes, renal calculi, pancreatic stones, calcification in the ribs, cartilage or transverse processes, and opaque material in the bovel, any of which may be exhibited within the shadow of the gall bladder. However, the localized transradiant or opaque areas produced by gall stones tend to maintain a constant from and situation in all films, whereas those due to other causes are likely to change in one or another respect.

It is obvious, then, that cholecystograwhy is pimarily a test of function at the time of examination, and only in exceptional cases is a means of demonstrating disease directly. X-Ray reports are usually confined to three forms: (I) normally functioning gall bladder, (2) poorly functioning gall bladder (when the shadow is persistently faint), and (3) non-functioning eall bladder (when a shadow of the viscus does not appear). Evidence of stones may be associated with any of the theee varieties, and 
is so reported.

Notwiths tanding the high dependability of cholecystography as shown by statistics, At would be a grave abuse of the method to recomend or aiscourage operation on the basis of this test alone. A catient is not merely a contribution to a statistical table but a subject with complex elements which cannot be tabulated; he should be considered independently of all others by the surgeon and clinician, who should crant to the cholecystoEraphic opinion only that weight which it deserves in the particular circunstances.

\section{INTUBATION}

As has been before-mentioned, intubation of the duodenum is used routinely by some men as a diagnostic measure while other men equally proficient deprecate its usefulness. Ferhaps some of the criticism of this procedure can be explained by Lyon's stotement, "I have often regretted that for the purpose of my own understanding of gall tract diagnosis it has been necessary to make a diagnostic medical draincge so highly technical, time consuming and laborious". This necessarily militates very distinctly against its adoption and wide aprlication by the profession in genera1.

To insure an understanding of this technic, a discussion of the types of bile is necessary. Four sterile bottles thabeled "A", "B", "C" and "D" are handy. All duodenal glass ware should be labeled "D" after the duodenal tube is in place, the duodenum is gently douched vith 75 cc. of magnesium sulphate by gravity instillation, and immediately wi.thdrawn by syphonage, and the proxianl end of the tube connected with the first sterile drainage bottle labelled "A". If it has been already proven that bile has escaped from the common duct, through an unphysiological sphincter into the 
(I7)

duodenum, we obriously cannot carry out a segregation of the usual three types of bile, and the tube is then attached to the sterile bottle labelled QC", indicating thet our fitst bile recovered is a mixture of gall bladder and liver biles, both being expelled from the common duct.

In all normal and in certain pathological gall tract cases the drainage sequence is very much of the some type, and is usually as follows: ShortIy after the magnesium sulphate solution reaches the fasting duodenum there occurs a relaxation of tonicity in the duodenal wall, and within $a$ few seconds to three minutes the normally closed ampullic sphincter described by oddi, likewise relaxes, and ithin approximately this same period bile begins to tinge the magnesium sulphate solution which is being recovered by gravity syphonage from the tube. When this bile tinged magnesium sulphate solution has been withdrawn, and is being replaced by a light golden-yellow bile, the tube is connected with the first sterile drainage bottle labelled "A". This " $E$ " bile, since it is the first obtainable from the closed sphincter, must be bile lying within the comon duct, and later becomes slightly diluted with bile from the cystic and hepatics ducts, with perhaps a few drops of gall bladder bile.

Drainage is then continued until the bile deepens to a darker shade of golden-yellow to yellow-brown with a viscosity between that of syrup and $a$ thin molasses. This is a mixture of the first portion of gall bladder bile mixed with the last of the common duct bile, and still further diluted with liver bile. At this point the tube is aisconnected from the sterile bottle labelled "A" and attached to a sterile bottle labelled "B", and the drainage continued. The color Eradually deepens and the fluid becomes more viscid as the purer gall bladder bile is being a ischarged, although it must be understood that this too is being constantly thinned 
out slightly by admixture with liver bile.

With a gall bladder possessing a normal muscular wall, and under a normal tension, this type of bile averages from I to 2.5 ounces, and is discharged under one magnesium sulphate stimulation in from ten to fifteen minutes, when it is gradually, al though sometimes quite abruply, reflaced be a very much lighter and thinner lemon to straw colored bile than either of the first two types. This is called" "C" bile and beliered to be freshly secreted and expelled liver bile. When this transition takes place a connection is made with a third sterile bottle labelled "C" and the drainage continued over a long a period as we may desire.

The amount of "A" or duct bile averages from 5 to not more than $30 \mathrm{cc}$. and is discharged rather rapidily within approximately five minutes. The "C" bile from the liver may continue to drain for a long time, even up to several hours, and several ounces may be secured if drainage is continued over a two or three-hour period. There are many interesting phenomena concerned in the method of delivery of these several biles. They vary in the manner of return and the velocity of their diacharge, whether it be intermittent drops, sudden spurts, or a steady, even flow.

Olive Oil and IO per cent solution of peptone are also effective gall bladder evacuating stimulants.

In all normal gall tracts all three of these different colored bile fractions should be perfectly clear and transparent and contain no microscopical cytology in the uncentrifuged specimen. In certain pathological cases in the earlier stages and of lesser severity, the gross colors of these bile may be identical with those of the normal, but there may be an increased sliminess or increased viscostiy due to partly dissolved mucus which may adhere to the glass observation window, and, in addition, there 
will be a small but appreciable amount of flocculent particles which can be readily picked out of the uncentifuged specimen with $a$ I cc. pipette and which microscopically present certain cytological features. In certain pathological cases the gross appearance of the biles may be very close to the normals except for a increased sliminess and evidence catarrh in the shape of nucopus flocculations. The microscopical cytology of these flocculi, together with the positive bacteriological evidence in in fresh spreads, later checked up by cultural growth, is the only clinical method that offers any possibility of definitely diagnosing the early Eall tract lesion.

Quantitative expression of the flocculi in regerd to diagnosis is therefore very important. Beyond the occasional floccule which occurs in normal cases, the resence of laree numbers of them is incicitive of catarrh. When the flocculi covers from I/ 8 to $I / 4$ of the botton of the bottle anc microscopically show only wucus strancis with fus cells and exfoliated epithelial cells, it is taken to indicete relatively rila catarrh and scored as plus I; where I/ 2 f the bottom of the bottle is covered by flocculi it is considered thet the patient has a roderately severe catarrh and scored as plus 2. Where the catarrhal or inflarwatory state is a severe one the flocculi anc wucus sliwe will cover $3 / 4$ or ali of the bottom of the bottle and this is scored 3. plus 3 or 4 . Whether this catarrh I inflammation is duodenal or eall tract or a combination of the two is aifferentiated by wether the mucus flocculi are or are not bile stained and by a microscopical study of the individual celis, differentiating the columni from the cuboidal or oval. as e ceneral rule the latter are to be interpreted as beine derived from the cuodenum. rhese flocculi may appear as fine enc feathery, or as thick clums or granular 
or shaegy messes. Sometimes were the viscosity or rucosity or the duodenal fluid or the bile may be so greet thet the mucoid flocculi cannot sink down to the bottom of the bottle, thoy will remain suspended or festooned dom at zarious levels.

In ali the cytological exwinations the extent and severity of the catarrh can be quantitatively estimated by the numbers of flocculi left unexawined in the specimen bottle when compared with the amounts used in one or more microscopical spreads; remembering that one or two drops from a jipette will practically supply e cover slip preparation, and give an enomous emount of cytological evidence. Therefore it vill be seen that the cytological evidence is of real importance only when considered from the quantitative estimation. A classification of A plus I to plus 4 usualIy covers this.

It is nost important that flocculi in bile be examined very fromply as cytolocical eviäence frow all points within a gall tract properly drained will show rather deep bile etaining of ell microscopical elements.

The portion of the tract that is aflicted petholosically is determined by the specimen bottle which contains the pethology, such as in cholecyochitis alone the ":" bottle wil conatin numerove flocculations wich will cease to appear or becove cistinctly les nurberous as the eall bladcier bile is being expelleà.

\section{DIFTERTITIAI DIAGNOSIS BY INANS OF INTUBTIONT}

Failure to recover "B" bile in a diannostic study makes one think of the following differential possibilities:

I. Cbstruction of the cystic duct due to the following causes: A (I) The muccous membrane of the cystic duct may be in a sta of 
inflarmatory edema.

(a) It may be choked by impisseted mucus or by very fine gall sand.

(3) Impacyed stones.

(4) Ray have occured localized irritation of the racemosed clands at the neck of the gell bladder.

B. (I) Aahesions involving the cystic duct.

(2) Angulations of cystic duct by rescure or otherwise.

(3) Stricture of cystic duct.

C. (I) By pressure exerted upon the cystic duct frow without, es by

I. Neighborhood tumors.

2. $\therefore$ enlared lymphe tic gland lying along the cystic duct.

II. The cavity of the gall bladder ray contain relatively little or no recognizable bile in the event:

A. That its entire capacity mey be filled with rultiple calculi of varying sizes.

B. Or. a large solitary stone around wich the 11 bladder has contracted.

C. Or the gall bladier mey be in a st te of complete atrophy or fibrosis. III. The bile contained in the Eall blacier way be so ultrastatic and of such tarry consistency as to be too thick to flow of itself, or the galI bIadder musculature may have becone to weakened to force it through the cystic duct.

IV. Adhesions angulating the gall bladder in such a manner as to prevent aischarge of its bile.

Enpyema of the gall bladder is takiest to diamose airectly by $r e d-$ ical drainace rovided the cell blagder is vechenic lly ble to ischarce. a specimen of its contente. Iyon sys, on several occsions I have been. 
ble to recove an ounce or nore of practically pure pus from patietns who, at operation, vere founo to lave an emyema of the gall bladder. Indeed I have been able to successfully drain several such cases and have brought about such a relative symptomatic recovery that operetion hes still been declined on the gart of thes atients, and I am convinced thet where it is possible to rrove by redical dreinage thet the is can be evacuated by way of the cuodenal tube this method rey be substituted as an aiternative in cases in whom sureery is contraindicated, and ray take ther over temprorary surgical contraindicitions until they can be better prepred to stanc the operative risk".

The total diacnostic impression frow a redical areinage of the gall tract is then developed from close study of the data found and recorded on the biliary drainage sheet, intercreted in the light of the history ana physical examination, and should embrace the findings which occurred in the stomech, the cuestion involved in a delayed duodenal transit time due to the various causes, and a direct study of tha bile anc the manner of its discharee, the promptness with wich " " and "B" biles appear, suenesting norme. 1 tonus, subtonus or hyertonus of gell bladaer musculature; and whether or not more than one stimulation ith regnesium sulphate or olive oil has been required; the velocity and character of the aischaree of "c" bile; the Gross apres.rance of the several biles; their color, consistency, viscosity, transparency, turbidity, flocculetions, mucus, etc; and especially the careful examinations into the cytology, freshly examined while still warm (epitheluim, whether bile stained, its susested source, Ius, leulocytes, crystals, concretions, morphous salts, rea blood corpuscles, rucus, bacteria and inflammatory cebris; into the chemistry of the bile (croIesterin, calcuir, rigments, lecithin, fat, effervescence on acicification); 
and into the bacteriolocy by cuituretion of each of the segregated samples of bile.

In answering the following question; "of what real diagnostic value is redicol drainacen" ve must consider the following points:

I. It cives us definite information as to the ratency of the ducts. If $A, B$ and $C$ biles are found, ve can be reasonobly sure there is no creat obstruction to the ducts. If efter severel dreinoces no "B" bile is found, an obstruction at, in or around the cystic duct may be found. 2. licroscopical blood, and no bile on stimulation with magnesion sulphate, in conjunction with other physical sicns, aids us in the diagnos is of malicnancy.

3. Real dark "B" bile means biliary stasus. Interoptosis can be placed under this heading.

4. Dark bile, with positive cultures, aidis in the diagnos is of the type and location of our infection.

5. Gall bladder sand may aid in the diarnosis of stone.

6. In cholecyotectory with recurrent symptoms, we can determine as to the ratency of the ducts, and whether or not infection is still resent.

7. It is another resn of locetine soci of infection.

8. It eids in the dionosis of tyrhoia corriers.

9. It can be used $a d$ an aid in the diagnosis of pncreatitis.

Io.It is an aid in the visueliz tion of the duodenum. A distorted cuodenal curve denotinc evidence of reriduacent achesions.

II. It aids in diognosis of certain types of heedaches.

I2.It assists in diagnosis of all lesions froducing rain in the viler richt quadrant. 
(24)

\section{FRODUCIS OF INTUBATION IYY SUGGEST STOMBS}

Drs. Louis M. Rousselot and Louis Bamen presented a note stating tiat durine the pest ten years there has been a eredual accurulation of evidence by various investigators tending to show thet the association of cholesterol crytals in duodenal bile and gall stone disease is rore than a coincidence.

Iyon, Hollander, lateer and Chester Jones all felt that the presence of many clumrs of cholesterol crystals probably signify the presence of gall stones. Recently Bockus presented a large, carefully studied group of cases and concluded that the presence of cholesterol crystals or calcium bilirubin pigment or both in bile obtained by a duodenal tube was positive criteria for tre diegnosis of call stones.

Similar studies heve been rerested end soremet laborated at the Iresbyterian Iospita]. recently. t techic wo been dopted tiot cre tIy simrifies and hastens the pasaee of the duodens tube. Al intubations are checked as to position by unf the florouocoric tole. The indentisicetion of tre crysteline elements and clauir bilirubin pignent in the bile sediment is not difficult.

It was specifically stated trat this test was not cone routinely on all cases of biliary tract disease but is reserved for those cases in which the diagnosis is vague and in which there is no confirmatory $x-r a y$ evidence. It is used almost routinely in jaundice cases to establish the presence or absence of bile in the duodenum.

The following conclusions were reached:

(I). The failure to obtain concentrated "B" bile after two or more drainages. is suggestive of intrinsic disease of the gall bladder.

(2). The absence of cholesterol crystals or calcium bilirubin pigment 
in concentrated "B" bile is fairly strong evidence gainst the presence of stónes.

(3) The finding of cholesterol crystals or calcium bilirubin nicment in dilute "A" bile or "B" bile is almost pathognomonic of the presence of gall stones.

\section{BIOOD CHENISTRY IN DIAGNOSIS}

In speaking of jaundice, we rust mention an etiological classification; and so McNee's classification is here given:

(I). Obstructive: in which there is a mechanical obstruction to the exprahepatic bile ducts with resultant absorption of bile pigments.

(E). Intra hepatic: (toxic or infective) in which there is an inability of the farenchymal liver cells to excrete the bile pigments in a normal ranner.

(3). Hemolytic: in which there is an excessive destruction of red cells so that bilirubin forms more rapidy than normal with consequent retention in the blood stream. It is also called hematacenous jaundice. An excess of bilirubin in the blood is called bilirubinemia.

All normal blood serum coitairs a certain anount of blood picment (bilirubin). It was Hymans Van den Bergh who first demonstrated that such traces of bilirubin in the serum are derived from extrahepatic sources. Bibirubin is derived from the disintegration of the hemoglobin of the red blood cells (normal consumption which i physiolocical) and from the cells of the reticule-endothelial system, especially those of the bone marrow and splenic pulp. The polygonal cells of the liver do not play any part in 1 ts formation. They simply excrete this pigment in the bile. For the purpose of analocy we cite the excretion of those halogen dyes which are used in gall bladder visualization. Van den Bergh also was first to point out 
that the amount of bilirubin in the serum becomes immediately increased when certain $d$ isturbances of the liver are resent or when intensified decomposition of the blood occurs. "direct" reaction is obtained with the blood of a patient only when the bilirubinemia results from the retention of bile in consequence of some nechanical obstruction. "n "indirect" reaction is obtainea with the blood of a gatient if the bilirubin is not excreted by the liver, but remains in the circulating plasma because of increased decomposition of the blood or altered hepatic function. This is the so-called "hemolytic" icterus in contrast to "mechanical" or obstructive icterus above described.

An increase in the amount of bile pigment in the circulating blood (above the normal amount) is a forerunner of jaundice. By tests we can predict that jaundice will develop long before the jellow flag of jaundice appears on the skin and before the sclera becomes discalored and before bile appears in the urine or before ve get the classical clay-colored stools. Ve can thus predict "latent jaundice" with reasonable certainty. Reese tests are also useful to ascertain the rrogress or decine in any case of jaundice already developed. Thus, when frequent records of this test are kept Eraphically they will reveal a "serum piement curve". In obstructive jaundice, as the obstruction lets ur the "curve" sinks lower and lower. A rising "curve usually means increasing obstruction. To the surgeon contemrlating operetion, a rising curve is interpreted as signifying that operation should be delayed because experience has taught him that a rising curve is a sign that hemorrhage will be profuse if operation is performed in such cases. The various tests for icterus index, namely, leulengrachts' and Bernheim's colorimetric tests for bilirubin have now given way to the 
Van den Bergh tost wich is both quantitative and cualitative.

\section{FRIATIONSHIF OF HEART AND GAII BIADDER DISEASE}

There seems to be conclusive evidence thet definite relation exists between certain cases of gall bladder disende nd hert disese. Surgeons occasionally use the chrese "cholecystic hest" with the idea that the gall bladder pathology bears a casual relation to the heart condition and symptoms. Graham recently accented this relation when he wrote, "ve have observed brilliant resultis in cases of heart discase following cholecystectomy after it had been determined that there was a pathological gall bladder. We know of suspected ceses of angina yectoris receiving complete and pemanent relief following cholecystectomy after it had been determined that there was a pathological gall bladder".

Acute choledystitis seems to have less disturbing influence as a rule on the cardio-vascular system. However the great pain incident to a. paroxysm of biliary colic seems wore definitely to upset the circulation.

\section{GAII STONES AND HEART DISEASE}

The presence of call stones is robably to be recarded as a by-roduct and an end result of inflammation or diserse of the gall bledder. Cholecystitis does not include cholelithiasis, the latter usually intimates the former. Whether inflermation is the sole elerient or even the chief elewent in influencine the keart and just how ruch part stones may rlay, are factors difficult to separate and evaluate. The eall bladaer is not an orcan to be redically or surically despised. Wile not much cood may come of it, certainly much evil may roceed from it, though one au thor recentIy referred to it as "a relatively uningortant appendage". viren diseased, it rarely lives unto itself alone. It must be kept in wind, then that when 
(28)

\& diagnosis is made of angina pectoris and the patient considered to have only angine pectoris, whereas the ancina rectoris is but a sympton related to and ceused by a chronic cholecystitis.

The clinical picture of inflamation of the call bledder is cremely varied. In the older text books enyhas is was placed on the la te and most severe evidences of inflammation. Nowedays, however, the desire should a lvays be present to diannose these cases much earlier than vas the custom then. The aim should be to rrevent as much as postible the develorrent of the serious and late effects which were formerly the chief foundation of the clinical picture. I will discuss here ordinary cholecystitis under two rain divisions acute and chronic.

\section{ACUTE CHOLECYSTITIS}

In acute cholecystitis the onset is usually suacien, sometimes with a chill. It occasionally begins auring the course of some other a isease as, for example, typhoid fever, acu te tonsillitis, etc. Iain, chiefly in the right upper quadrant of the abdomen, occurs early and is accomanied by muscular rigidity and tenderness vomiting, leucocytos is and fever. Sometimes the pain is cramplike with severe paroxysm. This is the type of pein which comonly occurs when stones are present. Crten, however, it is of a continous aching character and of a very severe nature. The pain is often referred to the back, especially in the recion of the ancle of the right scapula and the lower dorsal spine. It is unusual for it to be referred to the right shoulder. Usually when this reference of rain occurs in connection with gell bladder disesse reritonitis is resent. In tyxical cases pain is referred to the shoulder blade but not to the shoulder. Generally the rain of acute cholecystitis begins to subside in about 
(29)

twenty-four or forty-eight hours and usually after about ten days the symptoms are gone. Ordinarilly the fever is not high (above Ioz F.) and the chills are not severe unless a fairly extensive inflammatory involvement of the liver is also present. Jaundice is usually not present. When present it is usually slight. It indicates an obstruction of hepatic bile Which may be due to either stones in the heratic or common ducts, or, to an inflammatory obstruction of the intrahepatic ducts from edema, infiltration with leucocytes, etc. Graham has shown that apparently in all cases of cholecystitis there is an essociated hepatitis which is characterized be an inflammation around the intraheratic bile ducts, a rericholangitis. If this inflamation is severe enoush then some obstruction of the intrahepatic bile ducts will occur. The severity of'the jaundice may, therefore, be expected to be variable. The leucocytosis usually vories from about I2,000 to I8,000. Respiration is often lainful and may be somevnat limited on the right side.

If the cystic duct becomes obstructed an enlargement of the gall bladder occurs. The most common cause of ocstruction of the cystic duct is a stone. In acute obstruciive inflammations the gall bladder becomes filled ith pus and we have then to deal with an empyema of the gall bladder. In such cases the pain is likely to be paroxysmal and very severe auring the paroxysms. If the obstruction of the duct is relieved, either by the passage of the stone or by its falling back into the gall bladder, the pain usually ceases abruptly. If the obstruction rersists af er the stege of acute inflammation has subsided the contents become less purulent and more mucoid, distend the gall bladder and a hydrops of the gall bladder is then present. Jaundice is not of ten present in ceses of uncomplicated emryema of the gall bladder, and when present it is due ordinarily to an 
inflammatory blocking of the intrahepatic bile ducts.

\section{CIINICAI DIAGNOSIS}

The diagnosis of acute cholecystitis is usually easy because in the Ereat majority of instances a sudden severe attack of gain in the right upper quadrant most often indicates an acute inflarmation of the call bladder. The presumption of such a diagnosis is greatly strengthened if the patient hapyens to be middle aeed, sorewhet obese, and especially a woman Who has borne children. There are, however many other intraabdominal conaitions which may Eive rise to a clinical picture sugestive of acute cholecystitis. For example, perforation of a peptic ulcer may eive symptoms Thich closely imitate those of an ecute cholecystitis. The picture is often of a particularly puzzline nature, because if the condition is one of acute exacerbation of a chronic cholecystitis the history of chronic dysrersia ay be very sugestive of a reptic ulcer. Sometimes an $x$-ray examination after the rerforation of on ulcer reveals a collection of cas under the aiaphragm.

If it is possible to demonstrate a pneuroreritoneum in this way the diagnosis of perforated ulcer should be nade vi thout question. If the patient gives a history of revious attacks of lain like the present one the chances are more in favor of a diagnosis of recurrent acute cholecystitis than of a perforated ulcer. Another condition with which acute cholecystitis is often confused is acute appendicitis. Wany patients have been operated on for supposed acute appendicitis who were really suffering from acute cholecystitis. Ordinarily if one exercises care in taking history and in making the examination the differentiation is not difficult because the fain and tenderness of aprendicitis are almost always Lower than in 
acute cholecystitis. Again the history of recurrent attacks is a little more in favore of acute cholecystitis. In certo in cases in which the appendix is long and situated with the tip high under the liver it may be impossible to distinguish between the two conditions. Whenever in doubt it is better to operate in order to avoid the possibility of allowing an acute appendicitis to perforate and to develore the long train of serious consequences of such an event. Aprendieitis is of course much more comrion in young adults than is cholecystitis but too much reliance cannot be placed upon age differences. Acute pyelitis and renal colic are bothe cometimes confused with acute cholecystitis. An examination of the urine is of the greatest importance in order to rule out the possibility of such conditions. The presence of pus or blood in the urine vill of course speak in favor of - renal lesion. An $x$-ray examination of the kidney and ureter should be rade in doubtfui cases because a stone can usually by demonstrated in that. way.

Ferhaps the most serious confusion which is made in the diagnosis of acute chorecystitis is that which arises in connection with some of the acute cardiac catastrophes such as coronary thrombosis, angina pectoris, etc. It is particularly important to realize that one of these acute cardiac conditions may imitate closely the picture of acute cholecystitis because if a patient with an acute coronary thrombosis should be operated on, the reult of the operation is likely to be disastrous.

Acute cholecystitis is oceasionally confused with pneumonia of the right lower lobe and right-sided pleurisy. An examination of the chest should, however, serve to differentiate the wo conditions. An x-ray examination of the chest will be helpful in such cases. Other acute abdomipal crises such as lead colic, and the Eastric crises of tabes dorsalis may 
be confused with acute cholecystitis but a careful history and examination should tend to make the differential diagnosis possible. It has sometimes occurred also that a Riedel's lobe has been mistaken for an enlarged gall bladder and a diegnosis accordingly of an empyema of the gall bladder has been made erroneously.

\section{CHRONIC CHOLECYSTITIS}

Chronic gall bladder disease is so frequent that a very large portion of adult humanity gives evidence, either clinically or pathologically, of this condition. Like many other conditions, chronic cholecyatitis seems to be increasing. This apparent increase, however, may be mainly aue to the fact there are more people in the world today who have arrived at the age at which chronic cholecystitis is most. frequent, and also to the fact that the diagnosis of these conditions has been enormously improved, chiefly by means of the x-ray methods of examination, not only of the gall bladder itself but of the gastro-intestinal canal and also of the right kidney. It is now rather generally accepted that the most ocmmon organic cause of dysrepsia Is gall bladder disease rather then $d$ isturbances of the stomach or intestines.

The recognition of a case of chronic cholecystitis may be extremely easy or it may be so difficult that it can be determined only by a process of exclusion after resort to all the above mentioned modern methods of exaination. The easiest cases to diagnose are those in which the condition

os most advanced, and in which therefore the sym toms are most extreme. A patient of middle age with the characteristic build who complains of attacks of paroxysmal pain in the right upper quadrant of the abaomen associated ith nausea and voniting is very likely to have chronic cholecystitis, especially if the attacks of pain have no relation to the taktag of food, and 
if it is referred to the right scapula. The diagnosis vill of course be very much strengthened if in addition to these features, jaundice has been resent, Much more difficulty is presented in the diagnosis of the less advanced cases. It is very desirable that cholecystitis should be diagnosed in its early and mila forms before it has had time to produce the serious effects which give rise to the classical clinical pictures.

It is important to bear in mind that in almost all cases of cholecystitis it is the inflammation and not the stones which is doing the damage to the patient. Biagnostic evidence should therefore be directed to the detection of disasetof the gall bladder. The detection of tones is of secondary importance, although of course in a doubtful case the finding of gallstones by any method of examination is reassuring, and enables one more certainly to incriminate the gall bladder as the cause of the patient's symptoms. A presumptive diagnosis of stones can often be made with a fair degree of accuracy if the patients symptoms are severe and associated with definite paroxysmal attacks of pain followed by jaundice. In the milder cases, however, it is often imrossible to make even a reasonably accurate diagnosis of cholelithias is except by the use of cholecystography which reveal the presence of stones in a large proportion of cases.

\section{ADDITIONAI CLASSITICATION}

Another classification of gall bladder disease which is more comprehensive in its scope will be given here along with some of the differential points.

(I) ACUTE CATARRHAL INHECTIVE CHOLECYSTITIS with enlarged gall bladder must be differentiated from the colon distended with feces, a displaced kidney or a hydronephrosis, cholecystitis with enlargement of the gall 
bladder and paraxysms of pain may closely resemble hydronephros is $w$ ith painful crises. At first the enlared call bladder is rear-shaped, and later becomes enlongated, a floating kidney is more movable than the gall bladder and lesg fluctuating, and if the gall bladder is pushed backward, it returns when the pressure is removed, whereas a floating kidney remains where placed so long as the patient is recumbent. A floating kidney tends to slip away from the hand while the call bladder does not. A pyloric tumor is transverse to the axis of the gall bladder and is hard and tender. A tumor of the colon is not so vell outlined as an enlarged gall bladder, and is usualiy transverse to it. A fecal mass can generally be determined by the presence of fecal accumulations elsewhere, and their removal by an enama. 'In biliary colic the pain is more severe than in cholecystitis, while the tenderness, intestinal distention and enlargement of the gall bladder are mor evidence in cholecystitis. Great care must be taken to distinguish cholecystitis from appendicitis and pyelonephritis. In the case of cholecystitis the tumor cen be traced from above downward, while in that of aprendicitis it may be traced from below upward. Ius in the urine may clear up doubt between cholecystitis and pyelonephritis.

(2) MEMBRatrovs CHOLECTSTITIS must be diagnosed by the finding of casts and a history that closely resembles that of Eall stones, with which it is usually associated.

(3) SUPFURATIVE CHOLECYSTITIS may resemble subphrenic abscess, duodenal ulcer, or appendicitis in an abnormally located aprendix. In the case of cholecystitis, the tumor moves with respiration; duodenal ulcer gives the history of pain a few hours after takine food, and sometimes blood in. the stools. A perforated duodenal ulcer and suppurative cholecystitis may be indistinquishable. From appendicitis it must be differentiated along the 
lines already laid down. The resemblance of supparative cholecystitis to pyelonephritis, pneumonia or pleurisy on the right side may be close. If the gall bladder perforates and sets up a Eeneral jeritonitis this latter nust be distinquished from the peritonitis caused by a ruptured appendix or a perforated gastric or duodenal ulcer. The material found on opening the abdomen will clear up the doubt, and the history of the case in its early stage should be carefully inquired into for evidence of one or the other of these condition.

(4): PHLEGMONOUS and GANGRENOUS CHOIECYSTITIS uisually has a his tory of former attacks of cholecystitis. When there is a localized inflammation in the upper right quadrnat the differential diagnosis rests uron the points already mentioned. Then the case has assumed the characteristic of a general peritonitis the history of the attack ray throw liekt upon whether the peritonitis is the result of a ruptured appendix, a perforated gastric or duodenal ulcer, a cholecystitis, a pancreatitis, or intestinal obstruction. It is lways an extremely difficult task to make a diaenosis of phlegmonous and gangrenous cholecystitis, as distinquished from peritonitis due to other cauaes, such as those already named.

(5) CHRONIC CHOLECYSTITIS in its clinical manifestions, closely resembles cholelithiasis. The chief diagnostic points are attacks of pain as in gall stones, the presence sometimes of a pear-shaped enlargement of the call bladder, the absence of pain or tenderness during interval of attacks, and the fact thet jaundice is much less likely to occur then in attacks of gall stone colic; if it does, it is usuwally slight in decree. In chronic ulcerative cholecystitis gallstones are usually present.

\section{DIFFERENTIAL DIAGNOSIS}

Falpation of the abdomen will give information of ractically no 
value in the majority of cases of mild, chronic.choledystitis unless one has the opportunty of examining the ratient durine the time of a recurrent attack of inflammation. In some cases a definitely enlarged liver may be made out. In a case of hydrops, the enlarged gall bladier can usually be found; sometimes in patients with thin abdominal walls, stones within the gall bladder cen actually be ralpated. Tenderness on pressure of the lower doral vertebrae can sometimes be elicited:

There are many conditions which are likely to be confused with chronic cholecystitis. For that reason the differential diagnosis is sometimes extremely difficult, and agin mistakes may occur even in cases which seem to present rather typical clinical evidence of gall bladder disease. For that reason, it is better to examine with the $x$-ray nearly all patients in whom we suspect call bladder disease. There will be fewer surprises disclosed at operation if greater care is taken to use the more exact methods of examination in association with the ordinary methods of clinical examination

Chronic lesions of the stomach and duodenum, especially chronic pertic ulcer, are of ten confused with chronic cholecystitis. The characteristic pain of duodenal ulcer which occurs about two hours after a meal is usually not present in uncomplicated cases of chronic cholecystitis. In the latter condition, the pain is more likely to be faroxysmal when it is severe than when not severe. It is likely to occur without any particular reference to the taking of food. It occasionally happens, however, that the pain in a case of chronic cholecystitis will be relierd somewhat by the taking of food and alkalies, characteristics which are ordinarily thought of onIy in connection with peptic ulcer. When these characteristics are present in ancomplicated cases of cholecystitis, they are probably due to an existing hyperchlorhydria. When vomiting occurs in ulcer cases, 
the pain is usually relieved. In typical cases of cholecystic disease, the pein is not relieved by vomiting. It must be remembered and emphasized, however, that in about 4 per cent of cases of gastric and duodenal uloer, chronic cholecystitis is present. One should therefore always be on his guard to suspect the possibility of a combined lesion. Other lesions of the stomach also, such as cercinoma, etc., may present symptoms suggestive of chronic cholecystitis. Iikewise, cases of diverticula of the duodenum may sometimes present symptoms similar to those of diseased gall bladder. For these reasons, it is a good idea in the majority of cases of suspected chronic cholecystitis to examine the alimentary canal with the barium meal and roentgen ray. Conversely, it is a good idea also to examine most cases of suspected peptic ulcer and of other upper abdominal conditions by means of cholecys tography. Larimore and Graham, for example, had two cases in which the symptoms were suprosed to be due to diverticula of the duodenum, but which were really due to chronic cholecystitis. The gall bladcer was removed in both cases with complete relief of symptoms, and the supposed diverticula were found to be pseudodiverticula.

The various inflammations of the liver of ten present great dificulty in arriving at a decision as to whether or not the symptoms are due to chronic cholecystitis or to a liver disease inderendent of the gall bladder. Since the various types of cirrhosis of the liver are often confused with cholecystitis it should be noted that the presence of ascites and of other evidence of portal obstruction, such as enlargement of the spleen and aistension of the veriumbilical veins should all speak in favor of $\theta$ cirrhosis rather than of a chronic cholecystitis: 
Sychilis of the liver is of ten accomponied by rain end jaundice, and it may therefore closely imitate cholecystitis and cholelithias is. If nodules on the surface of the liver can be felt and a positive Wassermann or Kahn reaction is present, the presumption will be considerably in favor of hepatic syphilis. In ylephlebitis anc liver abscess pain is usually absent or of a very different tyye from that of a typicel case of cholecystitis. loreover, the fever and chils in pylerhlebitis and liver abscess are cheracteristio features which are not often present in uncomr licated cholecystitis. Unfortunately, X-ray examination even by c olecystocraphy is often of very little hely in the differentiation of cholecystitis from various hepatic diseases because the heratic condition itself often prevents the developrent of a well-marked shadow of the gall blacider, even in conditions in which the ga l blader is relatively normal.

It is difficult to state with certainty how often chronic cholecystitis is confused with a chronic inflammation of the appendix. Indeed, as every one knows, it is vary difficult to conclude what degree of chronic change in the pryendix may be ssociated with symptoms. For that matter, the same way be saia of the gall bladider, but to a less dekre. There are, however, definite cases of a chronicolly diseased arrendix which are relieved by the removal of the appendix. Freiaps it is more important to realize that probably in a mojority of cases of soecalled "chromic" appendicitis, the symptoms are usually due to something eise and often to a chronically diseased call blader. A careful X-ray exrination made by a skilled roentenolo ist is of the utrost helr in decidin wether or not there is an actual chronic argendicitis resent of a kind wich is likely to procuce symp toms.

The visceroitotic individual who is never well but yet never cuite sick, often has vague distressing pains in the upper abdoren which are 
sometimes referred to the region of the gall blacider. Choleoystography will also serve to rule out or establish the diagnosis of choleçstitis with more certainty in such patients than any otrer method of examination.

Carcinoma of the hepatic flexure has sometimes been mistaken for chroniccholecystitis because of cremplike ain coming on in the uper right quadrant. An X-ray examination uitr a barium eal should, however, Eive so characteristic a picture in a c se of carcinomi of the colon that this netrod of exemination would serve to estoblist the diacnosis or to rule it out.

Fyelitis, pyonel hrosis, kidney stone, hyuronehrosis, etc., may all cause symptoms which are strongly sugestive of chronic cholecystitis when they occur on the richt side. Usuelly, however, they can be excuded by a careful history and coreful physical examintion, which should incluce not only an examination of the urine but a roentgen ray examinetion by pyelogrephy as well. If an enlarged kidney is felt on the right side of course the presumption is greater that a kianey lesion is present than that there is $\theta$ cholecystitis.

cute pleurisy, either pyogenic or tuberculous, when it occurs on the riglt side, moy cause pain which is succestive of cholecystitis. It is usuall wore likely to be confused ith acute rather than chronic cholecystitis. An exmination of the chest would serve to rule out the possibility of a pleurisy.

It is the usuel opinion that stones hich are found in the cystic auct are forced through from the call bladder. Sweet, however has produced some evidence which indicates that rerhaps in many instances stones are formed in the cystic duct and that they later dror into the call bladder. 
The typical clinical picture produced by this conaition is that of the so-called "biliary" colic. This is characterized by a sudden onset of severe gain in the right upper cacidrant of tre abonen. The pain is often of the most intense aconizing kind. Associated with it is sometimes a feeline as if the liver were about to burst. The fain occurs in paroxysms with soreness remainine in the internissions. It $i$ of ten referred to the right scapula and to, the region of the lower dorsal spine. In some cases the pain is rost intense in the mid-epigastrium instend of the right upper quadrant and occasionally it is in the left hypochondrium. The in is sometimes so severe that sudden death has occurred in considerable number of instances durine a raroxysr. This event is more likely to occur in patients whose biliary disense is associated wit severe cardiorenal disea. Unless relieved by morphine the poroxysms of poin continue intermittently for severel hours. In some cases, however, in may not be a notewort: $y$ feature, at least it my not occur in severe raxysms and its onset may not be sudden. Nausea nd vomiting are nearly always present durine biliary colic. Tenderness and ricidity of the abdominal muscles are made out on palation. After the attacks have subsided somewhat it may be rossibl to ralpate an enlared liver which is tender, and the call bladder ray also be felt to be enlareed. If the stone in the cystic duct has caused obstruction a condition of either erryema or of hydrops of the gall bladier ensues, unless the wall of the gan bladder is so scarred with fibrous tissue that it is incapable of aistention. Jaundice is seen only in those cases in wich the inflermation $\mathrm{h}: \mathrm{s}$ extended $u$ to involve the liver, or in those coses in which a stone in the cystic duct is comliceted by the rresence of a stone 
in the cormon duct. Woderate fever, leukocytosis and occasional chills are present durine the period of colic.

The diagnosis of a stone irracted in tie cystic duct, apart from tie more cenerel diagnosis of biliary colic, is of imortance only in those case! in hich a mucous fistula has followed the surgicel drainage of the gall bladder and in those cases in which the sureeon at operation is conftonted With a distended vesicle.

Whe presence of : stone in the comon cuct is nearly always associated with a considerable amount of inflamation, not only in the coll blader but in the intraneratic aucts as well. In the majority of instances when the presence of the stone in the cormon duct is first recognized, the gell bladder has already become ereatly fibrosed becouse of the lons-standing cholecystitis. This observation was expressed in the now farous Courvoisier's law. "With obstruction of the choledochus by stone, distention of the gall bladder is rare; the organ is usua ly shrunken. "ith obstruction of other kinds, on the contrary, distention is the rule; shrinking occurs in only one-telfth of the case". The fibrosis is not lirited to the gell bladder but is found also to involve the ducts thenselves. This mejr. $b=$ so extreme as to cause a stricture. Other complications are the occurrence of fibrotic changes in the liver with soretimes a develorment of a welmarked biliary cirrhosis.

The digenosis of stone in the comon bile duct is generglly essy when there are present the tyrical features of rejeated attacks of biliary colic foldwed by deer jeundice, chills nd fever. 'he chief difficulty is in differentiating between a jaundice caused by obstruction of the comron duct by stone and an obstructive jaundice of some other cause. When the jaunaice is caused by maliennt disease, which is uncorrlicated by stones, 
the symptom develop insidiously nd the icture is in marked contrast vith the tyyical picture of stone in the comon duct. Again in malignant disease the jaundice is procressive instead of intermittent and pein is much less pror inent then in calculous obstruction. is is shown in the application of functional hep tic tests to diacnosis, the use of phenol. tetraiodophth lein as a functional test has rroved of great velue in differentiating between obstructive jaundice due to stone and that a due to malignant disease. When calculi nd carcinora coexist te dirficulty in diagnos is very great. It is usu lly bettey to meke the diagnosis of colculous obstruction and to advise lap rotomy because it occasionally hal that cases that wexe diagnosed as malign nt obstruction and perhaxs regarded by medical attenáants as hopeless, have been found on laparotory to be due to tre presence of $a$ celculous obstruction and, therefore, amenable to sureical treatment. Cases of calculous cholecystitis with : chol ngitis and hepatitis causing jaundice sometimne reselbles the ricture of a stone in the conmon auct so closely that a differentiation can be rave only at pperation when the opportunity to explore the common duct presents itself. Those cases in which the intermittent fever is consicious are sometimes confused ith malaria but the leukocytosis, the absence of rarasites in the bloo, and a long-standing history supgestive of disease in the biliary tract, should serve to favor the oicenosis of calculous obstruction $r$ ther than m laria. The various cirrhosis of tie liver ere sometimes conous d with calculous obstruction, but the tyrical biliery colic and the intermittent chills and fever are usually bsent in the former conditions. Sometimes the jaundice associ ted with acute intoxications of the liver as for example salvarsan poisonine and the condition of so-called "acute" yellow atrophy have been mistaken for acute calculous obstruction of the 
common duct. In these conditions of intoxication of the liver the characteristic biliary colic and the intermittent chills and fever are not conspicous In herolytic jauncice te discoloration is not so interse. Sile licrent is not found in the urine. Where is but little pein and there is an incre sed fragility of the red blood cells to hemolysis in salt solution.

There is one type of cese which presents rather characteristic features and in which it is very important to establish a diacnosis. If after a cholecystectomy for a calculous cholecystitis the ratient has attacks of biliary colic with intemettent jaundice and fever, it is elmost certain ie is suffering from a stone in the comon duct hich was overlooked at the former operation. It is possible that in some of these cases a ney stone has formed. But it seems to us that rost of the evidence is in favor of the idea that the stone was overlooked, unless lon interval has elapsed between the oreration and the recurrence of the syn tors. ctricture of the duct from scar tissue ill also give a clinical picture wich sometimes resembles that of a stone. If the symptoms are due to a stricture Which has followed an operative injury to the duct during the performance of a cholecystectomy, there will usually be obtained a history of a profuse aischerge of bile after the operation, continuing somewhat intermittently for periods of weeks at a time.

A number of othe conditions, which must be mentioned in thinkine of the differential diagnosis of the aforementioned conditions are: spatic colon, intestinal allery, lesions of tre sline, hemolytic icterus, slippin rib, the specific infections including parasites, torsion of the gall bladder, acute catarrhal icterus, stone in the heratic ducts, benicn and malignant stricture of the ducts. 
(44)

\section{BIBLIOGRAFHY}

Avarez, W.C. (and others): Gall bladder infections, Jour. Am. lied. Assn. I923, 8I, 974.

Bain, Wiagnosis and treatment of subacute cholecystitis, Lancet, I: 495-496, Mar. 9, '29.

Barksdsle, G.H. Diagnosis of gall bl dder disease, west Vireinia I.J. 24: 223-227, lay, '28.

Behrend, H. Diegnosis and treatment of $g$ II bladier disease, Am. Jour. Surg. July, :30: 9: I3I-I34.

Berger, H.I. Blood diagnosis, Battle and co. St. Louis, lio.

Blackford, J.K. and Dwyer, L.F. Gastric symptoms with particular reference to gall bladder disease, Jour. 'm....ed. 'ssn. I924, 83,418 .

Blahd, r.E. Gall bladder snd biliary ducts,

New York led. Jour. June 2, IOI7, cv, I033.

Boyd, william: Studies in call blader pathology, British Jour. SUrE. I922, IO 337.

Euckbinder, J,R. Diagnostic roblems of early cholecystitis,'

S. clin. North Imerica, 7: 795-790, June, 127.

Cheney, N.E. Diagnosis of gell bladder disease, Am. Jour. Ned. Sc. IgI7, cl.iii. 
(45)

Davis, Trancis: Nomal cholecystography,

Britishled. Jour. June 4. I9\%.

Dunn, A.H. Gall bledder disturbence,

Am. Jour. Sure. xxxi, no. 8.

Pritz, I.H. Diagnosis of ell bladder diseese

Jour. Iowa led. Soc. I8: 462-464, Dec. ' 28 .

Frommer, E.M. Differential diagnosis and surgical tratment of gall bla der disease, Clin. led. and Surg. 35: 792; 877; 28.

Gorman, J.J. Diagnosis and treatment of gaj.l bladder disease, southwestern ed. I4: 528-53I, Nov. 30 .

Graham, tivarts Ambrose, Disease of the gell bladder and ducts, Lea and Febinger, I928.

Grey, Fenry, natomy of the human body,

Lee and Febiner; Fhiladelrhia, Ioso

Mess I.R. X-ray in the diagnosis of g:II bla der disease, Canadian N.A.J. 29: 39I-396; Oct. 133.

Hof fmank.H. Diagnosis of gall bladder disease, Minnesota led. Jour. Lar. 132; I5: I44-I49.

Hudson, F.I. and Lake, H.F. Importance of early diagnosis of gall bl dder disease, Clin. led. and Surg. 34: 253-262, April, '27.

Job, T.T. The anatomy of the duodenal portion of the bile and pancreatic ducts, net. Rec. I926, 32, 212. 
Jones, C.M. The rational use of duodenal drainage, Arch. Int. Ned: I924, 34, 60 .

Larimore, J.W. Cholecys to ghar hy: oral edministoration of sodium tetraiodophenolphthalein, Radiology, I926, 6, I56.

Levis, Jean, Jiggnosis of gall blidder äisease, U. F. Frior Co. Inc. Vol. I929 I. 23-29.

Love, M. Differential dianosis of call bladder diseace, Nebraska led. Jour. I8: 86-9 I kexch, 33.

Iyon, B.B.V. Dizgnosis and renacenent of $g$ II bladder disease, Am. Jour. Digest. Dis. nd Kutrition; I: I8-28, Nar. 34.

Lyon, B.B.V. Non-surgical dreinace of the gall tract, Lea and Febinger, Fhiladelyhia, I923.

Iyon, B.B.V. Diagnos is of gall bladder aisease, Jour. "mer. led. Assn. Nov. 27, I9IO.

Iyon B.B.V. Diagnos is of gall bladcer disease, Jour. Am. Med. Assn. Jan. 24, IO20.

Nayhew, J.M. Diagnosis and differential diegnosis, Nebr. I.J. I2: 327-325, Sept. 127.

Lc Celvey, J.S. Diagnosis and surgical treatment, Texas state Jour. Nied. 24: 269-273; Aug. '28.

NcCrae, T. Medical aspects of gall bladder disease, Tr. Coll. Ihys. Fhiladelphia, IgI7, xxxix. 
lix, C.I. Symy toms of eqal bladier disease,

Tr. Chicago soc. Int. Med. IgI7, I-ii.

loynihan, The gall bladaer and its infections, British Yed. Jour. Igae I,I.

Nichols, B.H. Differentinl dirgnos is of eall bladder disease, led. Clin. North America; sa: 722-73e, Feb. 33.

Nichols, B.H. Differentiel diennosis of ell bledaer disease, Jed. Clin. of North merice: I7: I059-I069, Jan. I934.

Olin, I.A. Cholecys toeraphy,

Illinois Ned. Jour. 65: 57-64, tan. 134.

Eancoest, H.K. Roentcen diegnosis of . Il bladder disease, Tr. Coll. Ihys. Ihiladelpiis, I9I7, xxxix.

Ihillips, John, The aicgnosis an treatrent of diseases of the liver end biliary tract, Oxford University Iress, Nev: York, I930.

Fumpelly, $\%$.C. Indiestion; its relntion to gell blader disease; Clinical spect of cholecystic disense, Jour. led. Assn. Georein, I7: 5I4-5I9, Nov. '28.

Ransom, B.B.jr. Diagnosis and treatrent of cancer of the gall blacder, Jour. Med. Soc. New Iersey, 3I: Ín7, Nar. 34.

Rehfuss, N.E. Clinicel diagnosis of cel? bladder disease, Fennsylvanio Ned. Tour. At ens, ry: In $I 6, x x$.

Rehfuss, L. I. Differential diecnosis of kal bl cier disease, 'nn. Int. led. I: 80-9: Aus. '27. 


\section{$(1 \leq 8)$}

Roberts, R. Di chostic re tions betwen 11 blader ond hert, Illinois led. Tour. 56: 3I7-32I, Tov. 10.

Rolleston, Sir Hum hry Dovy, Dice ses of the Iiver, call bladder, and bile ducts, Racrillen na Co. Ita. Iondon IoI2.

Rousselot, I.I. and Bauman, Iouis: Cholesterol crystals an calcium bilirubinate eranules: Jour. Amer. Med. Assn. Vol. IOO, F. 254: Jan. 133.

Ryan, ".J. Diaknosis and differential diagnosis of gll bladder diseae, S. Clin. North rerica I4: I85-I97; Feb. '34.

Rousselot, I. H. and Beuman, L. Diegnostic value of bile obtained through tie duodenal tube, ann. SurE. Tuly 133; 98: I40-I50.

Sacks ldolph, Diagnosis of gall bisdder dise se,

Nebr. Stete led. Jour. Aug. IOA, , No. 8, 225.

Smith, J.H. Dingnosis of cholecystitis,

Vircinia led. lonthly 55: 40-43, vril, ' 20.

Enov, Diagnosis of hydropo of the geli blader by Grahan test (choleeys tograrhy), Jour. mer. Ned. Assn. (0: I5:6; lay I2, 28.

Soper, H. Dingnosis of 811 bleduer disesen, mer. Jour. Ieả. Sci. "ug. IOI8 I66, No. $2,205$.

Swelm, H.A. Diegnosis of Ell bladder disease, Northwest led. 29: 247-25I, June, 30. 
Whipple, Allen, 6. Surficn retholore and dianosis of the biliary tract diseases, Melson Surery-- Ool. V. Thomes $\mathbb{R}$. Ison and Sons, New York, ${ }^{\text {T. }}$.

wright, F.J. Jiacnosis of gall bladder äsease, Virsinie Med. Montriy, 56: 2579259, 'uly, 129.

ilson, J:C. ledicel dianosis of Eli bledder disesse, Ned. Diag. Feb. I9II.

Zinniger, M.M. Flea for early aifenosis otd sureical treatment of acute gall bladder disesse, Ohio state led. Jour. 29: 629-23I: "pril, '33. 